\title{
Değişik Varyans Oranlı Normal Populasyonlardan Alınan Değişik Örnek Genişliğindeki İki Örnekte Student-t, Welch ve Ayıklanmış-t Testlerinin Uygulanması ile Elde Edilen I. Tip Hata ve Testin Gücü
}

\author{
Ensar BAŞPINAR'
}

Geliş Tarihi: 02.01.2001

\begin{abstract}
Özet : Bu çalışmada, değişik varyans oranlı populasyonlardan alınan iki örnek ortalaması arasındaki farkın Student-t, Welch ve \%5 ayıklama uygulanmış Ayıklanmış-t Testleri ile karşılaștıriması sonucu elde edilen I. Tip hata olasılikları ve testin gücū ele alınmıştır. Bu amaçla, populasyon ortalamaları arasindaki farklar $\delta_{1}=0.0,1 \cdot 0,1.5,2.0$ standart sapma olacak şekilde 10000 simulasyon denemesi yapilmıștir. Her bir simülasyon denemesinde sỏz konusu populasyonlardan, örnek genişlikleri eşit ve farklı olan örnekler alınmış ve bu örneklere söz konusu testler uygulanarak gerçekleşen I. Tip hata olasiliklan ve testlerin gücü ampirik olarak elde edilmiştir. Sonuçta, örnek genişliklerine bağlı olarak populasyon varyansları homojen olduğunda her oç test, populasyon varyanslanı heterojen olduğunda ise Weich ve Ayıklanmış-t Testlerinin daha güvenilir olduğu görülmüştür. Ayrıca örnek genişlikleri arttıkça söz konusu testlerden ozellikle Welch ve Ayıklanmış-t Testlerinin populasyon varyanslarinin heterojenliğinden fazla etkilenmediği de gözienmiştir.
\end{abstract}

Anahtar Kelimeier : Student-t testi, Welch testi, Ayıklanmış-t testi, düzeltilmiş ortalama, ortalamaların karşılaștırması, I.tip hata, testin gưcü

\section{Type I Error and Power of Tests When Applying The Student's-t, Welch and Trimmed-t Tests to Two Samples of Various Sizes from Normal Populations Having Various Variance Ratios}

\begin{abstract}
In this study, Type I Error and Power of Tests were examined in two samples of various sizes from normal populations with various variance ratios when the Student's-t, Welch and Trimmed-t Tests with 5 percent trimming were applied. For this aim, the 10000 simulation experiments were run for each combinations of differences of the populations which differ from each other by $\delta_{1}=0.0,1 \cdot 0,1.5,2.0$ standard deviation. Each of these experiments was taken with samples of equal and unequal sample sizes and applied different tests. At the end of these procedures, Type l error rates and power of the tests was observed empirically. The 10000-simulation tests show that when the population variances are homogenous all of the tests when they are heterogeneous Weich and Trimmed-t Test would be used confidentlally. On the other hand, when the sample sizes were increased, Welch and Trimmed-t Tests were not influenced from the heterogeneity of populations variance.
\end{abstract}

Key Words: Student's-t test, Weich test, Trimmed-t test, winsorized mean, comparison of means, type I error, power of test

\section{Giriş}

Bağımsız iki örnek ortalaması arasındaki farkın test edilmesi, oldukça fazla karşılașilan bir konudur. Gözlemlerin normal dağılması ve eşit populasyon varyansına sahip olması on şartları altında, Student-t testi ile söz konusu örnek ortalamalarının karşılaştırıması yaygın olarak başvurulan yollardan biridir. Ancak, bu test istatistiğini kullanmada ikj temel problemie yaygın olarak karşılaşılmaktadir. Bu problemlerin birincisi normal dağılım on şartı, ikincisi de populasyon varyanslarının eșitliği on şartıdır. Çankü, pratikte özellikle psikoloji, ekonomi, tıp, diş hekimliği, eczacılık, gıda ve bazı ziraat konularında, bu on şartlardan bazen birinin, bazen de her ikisinin sağlanması pek mumkan olmamaktadır. Bōyle durumlarda kullanilmak üzere geliştirilmiş çeşitli yơntemler vardır.

Bu çalışmada, Student-t testi, Welch testi ve Ayıklanmış (trimmed)-t testi ele alınmış ve bunlanın, değişik varyans oranlarında eşit ve farklı ortalamalı normal dağılım kombinasyonlarından alınan değişik örnek genişliklerindeki örneklerin karşılaştırılması her bir kombinasyon için 10000 simălasyon denemesi ile yapilarak gerçekleşen I. Tip hata olasilıklan ve testin guca elde edilmiştir. Benzer bir durum da dağılımın normal olması ancak, populasyon varyansinin bilinmemesi halinde de geçerlidir (Devenport ve Webster 1970, Yuen ve Dixon 1973, Wilcox 1995, Wilcox at al. 1998, Anonymous 1998).

\section{Materyal ve Yöntem}

Çalişmanin materyalini, simülasyon tekniği ile uretilen tesadüf sayıları oluşturmuştur. Üretilen tesadüf sayılarından standart normal tesadü değişsenleri óretilmiş ve bunlar yardimiyla sirasiyla $N(0,1), \quad N(0,2), \quad N(0,4)$, $\mathrm{N}(0,6), \mathrm{N}(0,8), \mathrm{N}(0,10), \mathrm{N}(0,12), \mathrm{N}(0,14), \mathrm{N}(0,16), \mathrm{N}(0,18)$

\footnotetext{
${ }^{\top}$ Ankara Oniv. Ziraat Fak.Zootekni Bölümu - Ankara
} 
ve $N(0,20)$ parametreli onbir adet nomal populasyon elde edilmiştir. Bu populasyonların; $N(0,1)-N(0,1), \quad N(0,1)$ $\mathrm{N}(0,2), \quad \mathrm{N}(0,1)-\mathrm{N}(0,4), \ldots, \quad \mathrm{N}(0,2)-\mathrm{N}(0,1), \quad \mathrm{N}(0,2)-\mathrm{N}(0,2)$, $N(0,2)-N(0,4), \ldots$ ve $N(0,20)-N(0,1), \quad N(0,20)-N(0,2)$, $N(0,20)-N(0,4), \ldots N(0,20)-N(0,20)$ olmak azere ikili populasyon kombinasyonlan oluşturuimuş ve bu populasyon kombinasyonlarinın her birinden sırasıyla $n_{1}=n_{2}=20, n_{1}=n_{2}=40, n_{1}=n_{2}=60, n_{1}=20$ ve $n_{2}=40, n_{1}=40$ ve $n_{2}=20, n_{1}=20$ ve $n_{2}=60, n_{1}=60$ ve $n_{2}=20, n_{1}=40$ ve $n_{2}=60$, $n_{1}=60$ ve $n_{2}=40$ ornek genişliğinde örnekler alınarak sırasıyla Student t-testi, Welch testi ve dağılımların her ikj tarafindan $\% 5$ ayıklama yapilip. Ayıklanmiş-t testi uygulanmiștır; Bu ișlem her populasyon kombinasyonuörnek genişliği-varyans orani kombinasyonu için 10000 defa yapilip gerçekleșen I. Tip hata olasılıkları ve populasyon ortalamaları arasındaki farklar, $8=0.5,8=1.0$, $\delta=1,5, \delta=2.0$ standart sapma için uygulanan testlerin gọç değerieri, ret edilen hipotez sayiları saydıriliarak ampirik olarak elde edilmiştir. Welch ve Ayıklanmış-t istatistiği, dazeltilmiş serbestlik dereceli Student t-Dağılimi göstermektedir (Devenport ve Webster 1970, Yuen 1974, Wilcox 1986).

Student-t testi; bağımsız iki ömek ortalaması arasındaki farkın tesadüfi olup olmadığına ilișkin hipoțez testini,

$$
t=\frac{\bar{x}_{1}-\bar{X}_{2}}{\sqrt{\frac{\left(n_{1}-1\right) S_{1}^{2}+\left(n_{2}-1\right) s_{2}^{2}}{\left(n_{1}-1\right)+\left(n_{2}-1\right)} \frac{n_{1}+n_{2}}{n_{1} n_{2}}}} \text { ifadesine göre }
$$

hesaplanan $t$ istatistiğinin $\left(n_{1}-1\right)+\left(n_{2}-1\right)$ serbestilik dereceli t-dağılımı gösterdiğini varsayarak kontrol etme esasina dayanmaktadir. Welch testi ise ayni hipotezi, Student-t testindeki gibi hesaplanan $\mathrm{t}^{\prime}$ istatistiğinin,

$$
v^{\prime}=\frac{\left(\frac{s_{1}^{2}}{n_{1}}+\frac{s_{2}^{2}}{n_{2}}\right)^{2}}{\frac{\left(\frac{s_{1}^{2}}{n_{1}}\right)^{2}}{n_{1}-1}+\frac{\left(\frac{s_{2}^{2}}{n_{2}}\right)^{2}}{n_{2}-1}} \text { serbestlik dereceli t-dağılımi }
$$

gösterdiğini varsaymaktadır. Bu şekilde hesaplanan serbestlik derecesi kendisine en yakın kạçok tam sayıya yuvarianmaktadir (Zar 1999).

$x_{1}, x_{2}, \ldots, x_{n}$ bir populasyondan alınmıs $n$ deney ünitesinin sıralanmiş değerleri olmak üzere, $k$ defa ayıklanmış (trimmed) ve duzeltilmiş (Winsorized) ornek ortaiamalari strasıyla;

$$
\begin{aligned}
& \bar{x}_{k_{1} a}=\frac{1}{n-2 k}\left(x_{k+1}+x_{k+2}+\ldots+x_{n-k}\right) v e \\
& \left.\bar{x}_{k_{1} d}=\frac{1}{n}(k+1) x_{k+1}+x_{k+2}+\ldots+x_{n-k-1}+(k+1) x_{n-k}\right)
\end{aligned}
$$

ifadelerine göre hesaplanırlar. k defa düzeltilmiş sapma kareler toplami ve varyans ise;

$$
\begin{aligned}
\text { sKT }_{k d} & =(k+1)\left(x_{k+1}-\bar{x}_{k d}\right)^{2}+\left(x_{k+2}-\bar{x}_{k d}\right)^{2}+\ldots \\
& +\left(x_{n-k-1}-\bar{x}_{k d}\right)^{2}+(k+1)\left(x_{n-k}-\bar{x}_{k d}\right)^{2}
\end{aligned}
$$

$h=n-2 k$ oimak uzere, $s_{k d}^{2}=\frac{S K T_{k d}}{h-1}$ ifadelerine gore hesaplandıktan sonra, bağımsız $|k|$ ayıklanmış brnek urtalaması arasındaki fark lçin Ayiklanmıs-t istatistiği;

$$
t=\frac{\left(\bar{x}_{k a 1}-\bar{x}_{k a 2}\right)-\left(\mu_{1}-\mu_{2}\right)}{\sqrt{\frac{s_{k d 1}^{2}}{h_{1}}+\frac{s_{k d 2}^{2}}{h_{2}}}} \text { seklinde hesaplanir. Bu }
$$

şekilde hesaplanan Ayıklanmış-t istatistiği yaklaşık f serbestlik dereceli t-Dağılımı góstermektedir. f serbestlik derecesi,

$c=\frac{s_{k d 1}^{2} / h_{1}}{s_{k d 1}^{2} / h_{1}+s_{k d 2}^{2} / h_{2}}$ olmak azere $\frac{1}{f}=\frac{c^{2}}{h_{1}-1}+\frac{(1-c)^{2}}{h_{2}-1}$ ifadesinden hesaplanır. Ayıklanmış-t istatistiğinin kesin dağilimini analitik olarak elde etmek oldukça zordur. Ancak simôlasyon teknikleri ile dağılim hakkında fikir edinilebilmektedir (Winer 1971, Yuen 1974, Wilcox 1997, Zar 1999).

Çalışmada, tesadof sayllannın aretilmesinde ve gerekif hesaplamalarda, "Microsoft FORTRAN Power Station"da Fortran-90 Programlama dilinde yazılan programlardan yararlanılmış̧ır.

\section{Bulgular ve Tartışma}

Çalışmada ele alınan populasyon ortalamaları, varyanslan, örnek genişlikleri ve populasyon ortalamaları arasındaki farklara $(\delta=0.0, \delta=0.5, \delta=1.0, \delta=1.5, \delta=2.0)$ gore 10000 simálasyon denemesi sonunda elde edilen $L$ Tip hata olasilıkları Çizelge 1'de, uygulanan testilerin gą̧ değerleri ise Çizelge 2, Çizelge 3 , Çizelge 4 ve Çizelge 5 de topluca verilmiştir.

Çizelge $1^{\prime}$ de, değişik genişlikteki örneklerin alındığı populasyon ortalamaları arasındaki fark, $\delta=0.0 \quad\left(\mu_{1}=\mu_{2}\right)$ olacak şekilde dûşânătmăş ve 10000 simalasyon sonunda gerçekleşen I. Tip Hata olasılıkları Student t, Welch ve dağilımlarin her iki tarafından da \%5'lik ayıklama oranı uygulanmış Ayıklanmış-t testleri için ampirik olarak elde edilmiştir. Orneklerin alınmış oldukları populasyon ortalamaları eşit olmakla birlikte, varyansları arasında sirasiyla, $1,2,4,6,8,10,12,14,16,18$ ve 20 kat fark olmasina rağmen ornek genişlikieri eşit $\left(n_{1}=n_{2}=20,40,60\right)$ olduğunda boton testlerde I. Tip hata olasiliklarinin deneme başında kararlaştırilan $\alpha=\% 5$ ten aşırı bir sapma göstermedikleri Çizelge 1'den anlaşılmaktadir. Bu durumda, populasyon varyansları arasında 20 kat fark (standart sapma cinsinden) olduğu veya populasyon varyanslan bilinmediği durumlarda ornek genişlikleri eșit olmak kaydiyla, ele alınan testlerin $1-\alpha=0.95$ güven 
katsayısı lle kullanılabileceği sỏylenebilit. Ancak ornek genişliklerinin eșit olmadiğı durumlarda, Student-t testinin sadece varyans oranlan 1:1 olduğu durumlarda I. Tip hata olasiliğıni beklenen seviyede gerçekleştirebildiği, $n_{1}>n_{2}$ olması halinde (varyansı kọçok olan populasyondan alınan bireylerin çok olması halinde) I. Tip hata olasılığında aşın dussme, $n_{1}<\pi_{2}$ olmasi halinde de (varyansi boyok olan populasyondan alınan bireylerin çok olması halinde) I. Tip hata olasiliğında aşırı youkseime olduğu göralmektedir. Buna karşılık gerek Weich ve gerekse Ayıklanmış-t testleri 1. Tip hata olasiliğini bașlangiçta belirlenen $\% 5$ sininnda muhafaza etmektedirler,

Çizelge 2'de, değişik genişlikteki örneklerin alındığı populasyon ortalamaları arasındaki fark, $\delta=0.5 \quad\left(\mu_{1}=0\right.$ ve $\mu_{2}=0.5$ ) standart sapma olacak şekilde dussunulmúş ve 10000 simalasyon sonunda, uygulanan Student $t$, Weich ve Ayıklanmış-t testlerinin gą̧ değerleri ampirik olarak elde edilmiştir. Bu Çizelgede, populasyon varyanslari ve örnek genişlikleri eșit olmak kaydiyla ancak $n_{1}=n_{2}=60$ olması halinde testlerin gäcanoun govenilir gö sınirları içinde (\%75'ten bayök, Zar 1999) kaldığı görälmektedir. Diğer böton kombinasyonlarda gǘ̧ değerleri oldukça doşok olmaktadir. Ancak populasyon ortalamaları arasindaki farkin $\delta=0.5$ olmasinin, böyle bir sonuc elde etmede rolo olduğu da göz ardl edilmemelidir. Çanko ortalamalar arasındaki fark doşt0kçe gục değerlerinin de dossmesi beklenen bir durumdur (Akdeniz 1984, Zar 1999)

Çizelge 3'te, değişik genişlikteki orneklerin alindiğı populasyon ortalamaları arasındaki fark, $\delta=1,0 \quad\left(\mu_{1}=0\right.$ ve $\mu_{2}=1,0$ ) olacak şekilde doşanalmas ve 10000 simalasyon sonunda uygulanan Student $t$, Welch ve Ayıklanmış-t testinin güç değerleri ampirik olarak elde edilmiştir. Bu Çizelgede, populasyon varyanslan eşit olduğunda, ornek genişlikleri ve bunların kombinasyonu ne olursa olsun testin gücănôn her yöntemde güvenilir gáç sinurian (\%75<g0ç<\%90, Zar 1999) içinde kaldığı görülmektedir. Ancak, populasyon varyanslari arasında 6 kat fark olması halinde testin gücünän $n_{1}=n_{2}=60$ ornek genişlikleri kombinasyonunda batán yóntemlerde, $n_{1}=40, \quad n_{2}=60$ kombinasyonunda (büyok varyanslı populasyondan alinan ornek genişliği bayoblk olduğunda) Welch ve Ayıklanmış-t testlerinin, $n_{1}=60, n_{2}=40$ kombinasyonunda (boyăk varyanslı populasyondan alınan ôrnek genişliği koçăk olduğunda) da sadece Student-t testinin govenilir olduğu görulmektedir. Bu durum, populasyon varyanslan arasındaki fark arttıkça ve örnek genişliklerinin de böyok varyansli populasyon lehinde dengesiz olmasi halinde Welch ve Ayıklanmış-t testlerinin, Student-t testine göre daha govenilir oldukları seklinde yorumlanabilit.

Çizelge 1. Normal dağilım gösteren ikl populasyonda $b=0.0$ için eide edilen ampirik I. tip hatalar (\%)

\begin{tabular}{|c|c|c|c|c|c|c|c|c|c|c|c|c|c|}
\hline \multirow{2}{*}{$m$} & \multirow{2}{*}{$\mathrm{nz}_{2}$} & \multirow{2}{*}{$\begin{array}{c}\begin{array}{c}\text { Uygulanan } \\
\text { tst }\end{array} \\
\end{array}$} & \multicolumn{11}{|c|}{$a^{2}+: a_{2}^{2}$} \\
\hline & & & $1: 1$ & $1: 2$ & 1,4 & $1: 6$ & 18 & $1: 10$ & $1: 12$ & $1: 14$ & $1: 16$ & $1: 18$ & $1: 20$ \\
\hline \multirow{3}{*}{20} & \multirow{3}{*}{20} & Student-t & 4.9 & 4.9 & 5,3 & 5.3 & 5.5 & 5.5 & 5.5 & 5.3 & 5.8 & 5.4 & 5.3 \\
\hline & & Weich & 4.4 & 4.3 & 4.5 & 4.4 & 4.4 & 4.6 & 4.4 & 4.3 & 4.8 & 4.4 & 4.2 \\
\hline & & Ayiklanmis-t & 5,0 & 5.0 & 4,8 & 5.1 & 5.3 & 5.2 & 5.2 & 5.2 & 4.9 & 4.8 & 4.9 \\
\hline \multirow{3}{*}{40} & \multirow{3}{*}{40} & Student-t & 5.0 & 4.8 & 5.0 & 5.7 & 5.6 & 5.3 & 5.3 & 5.6 & 5.4 & 4.8 & 5.7 \\
\hline & & Weich & 4.8 & 4.5 & 4.6 & 5.2 & 5.0 & 4.7 & 48 & 5.1 & 4.7 & 4.2 & 5.0 \\
\hline & & Ayiklanmis-t & 4.9 & 4.9 & 4.7 & 4.8 & 4.9 & 5.3 & 5.1 & 5.0 & 4.5 & 5.0 & 5.1 \\
\hline \multirow{3}{*}{60} & \multirow{3}{*}{60} & Student-t & 5.2 & 5.1 & 5.0 & 4.8 & 5.5 & 5.3 & 5.5 & 5.2 & 5.6 & 5.1 & 4.9 \\
\hline & & Weich & 5.0 & 4.9 & 4.7 & 4.5 & 5.2 & 5.1 & 5.2 & 4.9 & 5.2 & 4.7 & 4.5 \\
\hline & & Aylklanmis-t & 4.9 & 5.0 & 5.2 & 5.2 & 4.7 & 4.9 & 4.8 & 4.9 & 4.9 & 5.2 & 5.2 \\
\hline \multirow{3}{*}{20} & \multirow{3}{*}{40} & Student-t & 4.9 & 2.9 & 1,6 & 1.4 & 1.1 & 1.1 & 1.1 & 0.9 & 1.0 & 0.9 & 1.0 \\
\hline & & Weich & 4.6 & 4.5 & 4.5 & 4.5 & 4.7 & 4.8 & 4.8 & 4.5 & 5.1 & 5.0 & 4.5 \\
\hline & & Aynklanmis-t & 5.0 & 5.3 & 5.1 & 49 & 5.0 & 4.7 & 5.3 & 5.4 & 4.9 & 5.1 & 5.1 \\
\hline \multirow{3}{*}{40} & \multirow{3}{*}{20} & Student-t & 5.0 & 8.3 & 11.3 & 12.9 & 13.3 & 14.8 & 15.1 & 15.4 & 16.3 & 14.9 & 15.5 \\
\hline & & Welch & 4.5 & 4.8 & 4,7 & 4.6 & 42 & 4.6 & 4.7 & 4.8 & 4.9 & 4.5 & 4.6 \\
\hline & & Ayılkianmis-t & 5.3 & 4.8 & 4.9 & 5.1 & 4.9 & 5.2 & 4.6 & $5: 1$ & 5.4 & 5.0 & 5,1 \\
\hline \multirow{3}{*}{20} & \multirow{3}{*}{60} & Student-1 & 4.7 & 2.1 & 0.9 & 0.6 & 0.3 & 0.3 & 0.3 & 0.2 & 0.1 & 0.1 & 0.1 \\
\hline & & Welch & 4.5 & 4.7 & 4.4 & 4.7 & 4.6 & 4.8 & 4.9 & 4.8 & 4.6 & 50 & 4.7 \\
\hline & & Ayiklanmis-t & 5.1 & 5,0 & 4.7 & 4.6 & 4.8 & 5.2 & 49 & 4.7 & 4.7 & 5.2 & 5.2 \\
\hline \multirow{3}{*}{60} & \multirow{3}{*}{20} & Student-t & 4.9 & 9.2 & 15.7 & 18.3 & 18.9 & 21.0 & 21.8 & 22.7 & 23.1 & 23.4 & 23.6 \\
\hline & & Weich & 4.6 & 4.1 & 4.8 & 4.6 & 4.0 & 4.5 & 4.3 & 4.4 & 4.5 & 4.5 & 4.2 \\
\hline & & Aykjanmiş-t & 5.4 & 5.3 & 4.9 & 5.1 & 5.3 & 4.9 & 5.4 & 5.3 & 4.9 & 5.2 & 5.5 \\
\hline \multirow{3}{*}{40} & \multirow{3}{*}{60} & Student-t & 4.8 & 3.4 & 2.8 & 2.4 & 2.0 & 2.5 & 2.2 & 2.0 & 2.0 & 2,3 & 2.1 \\
\hline & & Welch & 4.6 & 4.4 & 4.9 & 4.7 & 4.2 & 4.9 & 4.8 & 4.6 & 4.8 & 5.0 & 4.9 \\
\hline & & Ayiklanmis-t & 4.8 & 4.9 & 5.1 & 5.3 & 5.1 & 4.9 & 5.3 & 5,0 & 5.0 & 5.3 & 5.0 \\
\hline \multirow{3}{*}{60} & \multirow{3}{*}{40} & Student-t & 5.3 & 6.9 & 8.2 & 9.1 & 9.3 & 10.0 & 10.0 & 10.3 & 10.6 & 10.7 & 11.4 \\
\hline & & Welch & 5.0 & 5.0 & 4.8 & 47 & 4.8 & 4.8 & 4.7 & 4.9 & 4.6 & 5.0 & 5.2 \\
\hline & & Ayıklanmis-t & 5.2 & 4.7 & 5,4 & 5.1 & 4.7 & 4.9 & 5.3 & 5,0 & 4.9 & 52 & 4.8 \\
\hline
\end{tabular}


Cizelge 2. Normal dağıim go̊steren ikj populasyonda $\delta=0.5$ için eide edilen ampirik testin güeu $(\%)$

\begin{tabular}{|c|c|c|c|c|c|c|c|c|c|c|c|c|c|}
\hline \multirow{2}{*}{$\mathrm{n}_{1}$} & \multirow{2}{*}{$n_{2}$} & \multirow{2}{*}{$\begin{array}{c}\text { Uygulanan } \\
\text { Test }\end{array}$} & \multicolumn{11}{|c|}{$a^{2} 1: a^{2} 2$} \\
\hline & & & $1: 1$ & $1: 2$ & $1: 4$ & $1: 6$ & $1: 8$ & $1: 10$ & $1: 12$ & $1: 14$ & $1: 16$ & $1: 18$ & $1: 20$ \\
\hline \multirow{3}{*}{20} & \multirow{3}{*}{20} & Student-t & 33.8 & 24.2 & 16.1 & 13.3 & 12.1 & 11,2 & 9.5 & 9.1 & 8.6 & 8.5 & 8.0 \\
\hline & & Welch & 31.7 & 22.4 & 14.5 & 11.7 & 10.4 & 9.6 & 7.9 & 8.0 & 7.1 & 7.0 & 6,6 \\
\hline & & Ayıklanmiş-! & 34.1 & 24.3 & 16.7 & 13.1 & 11.2 & 10.0 & 9.7 & 9.0 & 8.5 & 8.1 & 7.1 \\
\hline \multirow{3}{*}{40} & \multirow{3}{*}{40} & Student-t & 59.0 & 43.3 & 29.0 & 22.7 & 17.8 & 16.3 & 13.3 & 12.8 & 11.9 & 11.3 & 11.3 \\
\hline & & Welch & 58.1 & 42.3 & 27.8 & 21.5 & 16.8 & 15.3 & 12.5 & 11,8 & 11.1 & 10.5 & 10,4 \\
\hline & & Ayıklanmis-t & 59.9 & 43,8 & 29.7 & 22.0 & 18.5 & 16.1 & 14.3 & 12.6 & 12.1 & 11.0 & 10.6 \\
\hline \multirow{3}{*}{60} & \multirow{3}{*}{60} & Student $t$ & 76.8 & 60.3 & 40.9 & 31.7 & 24.6 & 21.6 & 19.4 & 17.0 & 15.1 & 15,1 & 13.5 \\
\hline & & Welch & 76,3 & 59,7 & 40.1 & 30.7 & 23.6 & 20.6 & 18.6 & 16.0 & 14.3 & 14.4 & 129 \\
\hline & & Ayiklanmis-1 & 76.9 & 61.1 & 40.8 & 30.8 & 24.7 & 21.1 & 18.5 & 16.8 & 14.9 & 14.5 & 13.5 \\
\hline \multirow{3}{*}{20} & \multirow{3}{*}{40} & Student-t & 43,9 & 26.2 & 13.2 & 8.3 & 6.0 & 5.0 & 3.9 & 3,3 & 3.0 & 2.8 & 2.5 \\
\hline & & Weich & 41.7 & 32.9 & 23.5 & 18.7 & 15.0 & 13.7 & 12.5 & 11.4 & 10.8 & 10,6 & 9.4 \\
\hline & & Ayiklanmis-t & 42.3 & 34.2 & 25.1 & 20.0 & 16.5 & 14.6 & 13.7 & 13.3 & 11.1 & 10.9 & 9.9 \\
\hline \multirow{3}{*}{40} & \multirow{3}{*}{20} & Student-t & 44.4 & 35.6 & 29.1 & 26.3 & 24.7 & 22.9 & 22.3 & 21.0 & 21.2 & 21.3 & 20.4 \\
\hline & & Welch & 41,9 & 26.0 & 16.3 & 12.2 & 10.6 & 9.2 & 8.3 & 7.3 & 7.5 & 7.5 & 6.7 \\
\hline & & Ayiklaninis-t & 43.6 & 28.8 & 17.7 & 14.0 & 11.8 & 10.5 & 10.0 & 8.9 & 8.4 & $B .7$ & 7.9 \\
\hline \multirow{3}{*}{20} & \multirow{3}{*}{60} & Student & 47.8 & 26.9 & 11.1 & 5.9 & 4.0 & 3.0 & 2.2 & 1.7 & 1.5 & 1.1 & 10 \\
\hline & & Welch & 44.8 & 38.0 & 29.3 & 23.7 & 20.1 & 18.8 & 16.2 & 14.7 & 14.1 & 12.8 & 12.2 \\
\hline & & Ayiklanmis-1 & 45.7 & 40.0 & 30.0 & 25.1 & 21.6 & 18.7 & 16.6 & 15.7 & 14.4 & 13.1 & 12.4 \\
\hline \multirow{3}{*}{60} & \multirow{3}{*}{20} & Student-t & 47,8 & 41.7 & 36,2 & 33.9 & 32.3 & 31.8 & 30.5 & 29,8 & 29.3 & 29.1 & 29.4 \\
\hline & & Welch & 44.4 & 27.7 & 16.8 & 13.3 & 10.7 & 9.9 & 8.4 & 7.5 & 7.8 & 6.5 & 6.7 \\
\hline & & Ayskianmis-t & 48,0 & 30.1 & 18.4 & 14.4 & 12.1 & 10,6 & 9.9 & 9.0 & 8.6 & 7.9 & 8.3 \\
\hline \multirow{3}{*}{40} & \multirow{3}{*}{60} & Student-t & 67.7 & 47.6 & 27.8 & 20.3 & 14.8 & 11.7 & 10.1 & 9.0 & 7.9 & 7.5 & 6.3 \\
\hline & & Welch & 66.8 & 52.2 & 36.1 & 28.7 & 23.1 & 19.3 & 17.4 & 15.6 & 14.7 & 13.8 & 12.1 \\
\hline & & Ayiklanmis.t & 68.0 & 53.4 & 37.7 & 28.8 & 23.8 & 20.4 & 18.1 & 16.8 & 15.2 & 13.8 & 13.4 \\
\hline \multirow{3}{*}{60} & \multirow{3}{*}{40} & Student-1 & 68.3 & 53.2 & 38.8 & 32.2 & 27.0 & 23,4 & 229 & 21.7 & 20.6 & 19.0 & 18.8 \\
\hline & & Welch & 67.3 & 46.8 & 28.8 & 22,1 & 17.3 & 14.4 & 13.7 & 12,3 & 11.5 & 10.4 & 10.3 \\
\hline & & Ayiklanmiš-1 & 68.1 & 48.6 & 30.4 & 22,6 & 18.6 & 17.0 & 13.9 & 12.9 & 12.4 & 11.5 & 10.5 \\
\hline
\end{tabular}

Çizelge 3. Normal dağ̈ilim gösteren ikì populasyonda $\delta=1.0$ için elde edilen ampirik testín gücü $(\%)$

\begin{tabular}{|c|c|c|c|c|c|c|c|c|c|c|c|c|c|}
\hline \multirow[b]{2}{*}{$n_{1}$} & \multirow{2}{*}{$n_{2}$} & \multirow{2}{*}{$\begin{array}{c}\begin{array}{c}\text { Uygulanan } \\
\text { Test }\end{array} \\
\end{array}$} & \multicolumn{11}{|c|}{$\sigma^{2} 1: \sigma_{2}^{2}$} \\
\hline & & & $1: 1$ & $1: 2$ & $1: 4$ & $1: 6$ & $1: 8$ & $1 ; 10$ & $1: 12$ & $1: 14$ & $1: 16$ & $1: 18$ & $1: 20$ \\
\hline \multirow{3}{*}{20} & \multirow{3}{*}{20} & Student-t & 87.1 & 70.9 & 49.3 & 38.5 & 30.7 & 26.3 & 23.3 & 21.6 & 18.8 & 18.0 & 16.6 \\
\hline & & Welch & 85.9 & 68.8 & 46.3 & 355 & 27.6 & 23.6 & 20.8 & 18.8 & 16.4 & 15.6 & 14.3 \\
\hline & & Ayikianmiș-t & 87.5 & 71,2 & 49.8 & 38.3 & 30.7 & 262 & 21.9 & 20.9 & 19.0 & 17.4 & 16.0 \\
\hline \multirow{3}{*}{40} & \multirow{3}{*}{40} & Students & 99.2 & 95.2 & 79.9 & 645 & 550 & 47.1 & 40.8 & 36.9 & 32.7 & 30.7 & 27.8 \\
\hline & & Welch & 99.1 & 94.8 & 78,8 & 63.0 & 53.5 & 45.2 & 39.1 & 35.3 & 30.9 & 29.0 & 26.0 \\
\hline & & Ayiklanmis-t & 99.3 & 95.5 & 80.2 & 66.2 & 55.5 & 47.2 & 41.0 & 35.9 & 33.1 & 29.5 & 27.8 \\
\hline \multirow{3}{*}{60} & \multirow{3}{*}{60} & Student-t & 99.9 & 99.3 & 93.5 & 83.2 & 73.0 & 63.1 & 56.8 & 50.8 & 46.4 & 41.6 & 39.0 \\
\hline & & Weich & 99.9 & 99.3 & 93.1 & 82.4 & 72.1 & 62.0 & 55.8 & 49.6 & 44.9 & 40.3 & 37.9 \\
\hline & & Ayiklanmis-t & 100.0 & 99.4 & 929 & 82.5 & 71.9 & 64.4 & 57.0 & 51.1 & 46.1 & 42.5 & 37.7 \\
\hline \multirow{3}{*}{20} & \multirow{3}{*}{40} & Student-t & 94.8 & 81.8 & 55,9 & 38,4 & 27.9 & 21.5 & 17.3 & 14.1 & 12.9 & 10.5 & 10.0 \\
\hline & & Welch & 94.0 & 86.3 & 71.5 & 57.5 & 48.2 & 42.3 & 37.0 & 33.0 & 30.5 & 27.2 & 25.5 \\
\hline & & Ayliklanmis-t & 93.8 & $B 7.3$ & 72.3 & 59.8 & 50.3 & 43.8 & 38.5 & 33.8 & 31,3 & 28.4 & 26.7 \\
\hline \multirow{3}{*}{40} & \multirow{3}{*}{20} & Student-t & 95.0 & 85.1 & 68.0 & 58.5 & 51.2 & 46.3 & 42.5 & 40.0 & 37.6 & 36.2 & 33.8 \\
\hline & & Welch & 94.1 & 76.3 & 50.6 & 38.2 & 29.6 & 25.0 & 21.7 & 18.9 & 16.6 & 15.9 & 14.6 \\
\hline & & Ayiklanmiş-t & 95.0 & 78.9 & 541 & 40,5 & 31.9 & 26.7 & 23.7 & 21.1 & 18.5 & 17.6 & 16.2 \\
\hline \multirow{3}{*}{20} & \multirow{3}{*}{60} & Student-t & 97.2 & 86.0 & 57.4 & 37.8 & 26.3 & 18.3 & 14.3 & 10.5 & 8.9 & 6.9 & 6.0 \\
\hline & & Welch & 96,3 & 91.7 & 80,7 & 69,8 & 62.5 & 55.8 & 49.8 & 44.8 & 41.0 & 37.9 & 34.2 \\
\hline & & Ayıklanmış-t & 96.3 & 92.3 & 81.8 & 72.9 & 63.0 & 56.7 & 50.7 & 46.7 & 41.8 & 38.6 & 36.2 \\
\hline \multirow{3}{*}{60} & \multirow{3}{*}{20} & Student-t & 97.1 & 88.7 & 75,7 & 67.3 & 60.5 & 56.0 & 524 & 49.8 & 45.7 & 44.7 & 43.1 \\
\hline & & Welch & $96: 1$ & 78.1 & 51.8 & 38.1 & 29.9 & 25.0 & 22.0 & 19,3 & 16.4 & 15.4 & 14.6 \\
\hline & & Ayiklanmis.t & 96.7 & 81,9 & 55.3 & 40.9 & 32.8 & 26.4 & 23.8 & 21.0 & 19.3 & 17.0 & 166 \\
\hline \multirow{3}{*}{40} & \multirow{3}{*}{60} & Student-4 & 99.8 & 97.8 & 85.1 & 70.7 & 57.1 & 47.1 & 40.3 & 35.1 & 30.6 & 27.8 & 25.3 \\
\hline & & Weich & 99.8 & 98.3 & 89,7 & 79.7 & 68.4 & 60.6 & 53.7 & 48.5 & 44.1 & 40.4 & 37.8 \\
\hline & & Ayıklanmiş-t & 99.8 & 98.3 & 90.4 & 79.7 & 70.1 & 62.7 & 55.5 & 50.2 & 44.2 & 41.3 & 37,6 \\
\hline \multirow{3}{*}{60} & \multirow{3}{*}{40} & Student-1 & 99,8 & 98.0 & 87.4 & 77.4 & 67.1 & 59.8 & 54.3 & 51,3 & 46.7 & 43.9 & 39.8 \\
\hline & & Weich & 99.8 & 97.1 & 81.3 & 66.8 & 54.3 & 46.2 & 40.2 & 359 & 31.8 & 29.5 & 26,7 \\
\hline & & Ayıklanmis-1 & 99.8 & 97.0 & 82.9 & 67.5 & 56.5 & 47.7 & 42.2 & 36.8 & 32.7 & 30.0 & 27.5 \\
\hline
\end{tabular}




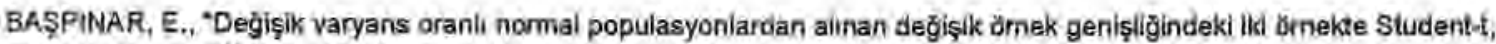
Welch ve Ayıklanmiş-1 tesilerinin uygulanmasi lle olde edilen L. ijp hata ve testlin glico"

Çizelge 4'de, değișik genișlikteki órneklerin alındı̃̃ı populasyon ortalamalan arasindaki fark, $\delta=1,5 ; \mu_{1}=0$ ve $\mu_{2}=1.5$ ) dacak şekilde doşandimus ve 10000 simolasyon sonunda uygulanan Student th Welch ve Ayiklanmis-t testinin $g 0 Q$ deg̃erleri ampirik olarak elde edlimiştir. Bu Çizelgede, populasyon varyansları eșit olduğunda, ómek genișliklen ve bunların kombinasyonu ne olursa olsun testin güconan her yountemde $\% 95$ in azerinde oldugu gorulmektedir.

$n_{1}=n_{2}=60 \quad(n=120)$ olduğunda, populasyon varyansiarı arasinda 18 kat fark olması halinde bile her OÇ test yönteminin de găc bakımindan birbirine yakin ve yakjaşık \%75 olarak gerçekleşirken, $n_{1}=20, n_{2}=40$ ómek genişliği kombinasyonunda (boyok varyansli populasyondan alınan birey sayısı fazla olduğunda) Walch ve Ayıklanmiş-t Testleninin goç değerleri, populasyonların varyanstan arasindaki fark 10 kat oluncaya kadar Studentt Testinden daha yoksek olarak gerçekleșmiștir. $n_{1}=40$ $n_{2}=20$ órnek genişliği kombinasyonunda (kücük varyansil populasyondan alinan birey sayısı tazla oldugunda) ise populasyonların varyanslan arasındaki fark 8 kat artincaya kadar Siudent-t Testi daha guclio olarak bulunmuștur.

$n_{1}=20, n_{2}=60$ örnek genişligi kombirasyonunda (bayak varyansli populasyondan alinan birey sayısi fazla oldugunda) Weich ve Ayiklanmiş-t Testlerinin gụç değerieri, populasyonların varyanslan arasındaki fark 16 kat oluncaya kadar Student-t Testinden daha youksek olarak gerçekleşmiştir. $n_{1}=60, n_{2}=20$ ornek genişliği kombinasyonunda (küçok varyanslı populasyondan alınan birey sayısı fazla oldugunda) ise populasyonlann varyansları arasindaki fark 12 kat artıncaya kadar Studentt Testi daha gocila olarak bulunmuştur, $m_{1}=40, m_{2}=60$ ve $n_{1}=60, n_{2}=40$ ornek genişlikleri kombinasyonlarında da benzer sonuçlar elde edlimiștir. Bunlarin bir sonucu olarak, populasyon ortalamaları arasindaki fark 1,5 standart. sapma oldugunda drnek genişlikleri eşit ve populasyonlann varyans oranlan 4 kat oluncaya kadar Student-t. Welch ve Ayıklanmış-t Testlerinden her hangi birl ayni guvenilirlikte kullanilabilirken, populasyoniarın varyans oranlari artıkça ve boyok varyansli populasyondan alınan birey sayıs) kaçak varyansh populasyondan alinan birey sayısından fazla oldukça Weich ve Ayikianmis-t Testleri, Student-t Testinden daha govenilir, kücok varyansil populasyondan alınan birey sayisi bayok varyansli populasyondan alinan birey sayısından fazla alduğunda da Student-t Testi, Welch ve Ayiklanmis-t Testlerinden daha govenilir olarak. kuflanilabilimektedis.

Çizelge 5 'de, degișik genişlikteki ormeklerin alındig̃ı populasyon ortalamalari arasindaki fark, $\delta=2,0\left\langle\mu_{1}=0\right.$ ve $\mu_{2}=20$ ) olacak şekilde doşunulmus ve 10000 simulasyon sonunda uygulanan Student $t$, Welch ve Aylklanmış-t testinin goç degerleri ampirik olarak elde edilmiştir. Bu Çizelgede, populasyon varyanslan eșit olduğunda, órnek genişlikleri ve bunlanin kombinasyonu ne olursa olsun testin gucanan her yöntemde \%100 oldugu gorulmektedir. Omek genişlikleri eşit olmak şartiyla, populasyonların varyans oranları arttikça her uç testinde găç değerlerinde de bir azalma olmaktadir. $n_{1}=n_{2}=20 \quad(n=40)$ oiduğunda, populasyon varyansian arasinda $10 \mathrm{~kat}, n_{1}=n_{2}=40(n=80)$ oldugunda, populasyon varyansları arasinda $20 \mathrm{~kat}$ fark olmasi halinde her oç test yönteminin de istenilen gúç değerlerine ulaştıkları görolimektedir.

Çizelge 4. Normal dag̀ilim gästeran iki populasyonda $8=1.5$ kịin elde edilen ampirik testin gücu (\%)

\begin{tabular}{|c|c|c|c|c|c|c|c|c|c|c|c|c|c|}
\hline \multirow{2}{*}{$n_{1}$} & \multirow{2}{*}{$n_{2}$} & \multirow{2}{*}{$\begin{array}{c}\text { Uygulanan } \\
\text { Test }\end{array}$} & \multicolumn{11}{|c|}{$\sigma_{1}^{2}: \sigma_{2}^{2}$} \\
\hline & & & $1: 1$ & $1: 2$ & $1: 4$ & $1: 6$ & $1: 8$ & $1: 10$ & $1: 12$ & $1: 14$ & $1: 16$ & $1: 18$ & $1: 20$ \\
\hline \multirow{3}{*}{20} & \multirow{3}{*}{20} & Student-t & 99.6 & 36.5 & 23.2 & 69.3 & 58.4 & 49.5 & 44.3 & 400 & 35.4 & 327 & 30.6 \\
\hline & & Welch & 99.6 & 959 & 81.2 & 66.5 & 55.1 & 45.9 & 40.5 & 362 & 31.6 & 29.4 & $27-1$ \\
\hline & & Ayiklanmist & 99.8 & 96.5 & 83.2 & 69.6 & 58.7 & 51.5 & 43,8 & 40.0 & 35.6 & 31.4 & 30.1 \\
\hline \multirow{3}{*}{40} & \multirow{3}{*}{40} & Student-t & 100.0 & 100.0 & 58.7 & 94.4 & 87.7 & 79.8 & 73.3 & 67.6 & 63.0 & 57.5 & 53.8 \\
\hline & & Welch & 100.0 & 100.0 & 98.5 & 94.0 & 86.8 & 78.3 & 71.8 & 66.1 & 61.1 & 55.3 & 527 \\
\hline & & Aysklanmıs-t & 100.0 & 99.9 & 98.7 & 94.3 & 87.9 & 80.6 & 74.2 & 68.3 & 61.8 & 57.6 & 53.4 \\
\hline \multirow{3}{*}{60} & \multirow{3}{*}{60} & Student-1 & 100.0 & 100.0 & 99.9 & 99,2 & 97,0 & 93.2 & 89.1 & 84.3 & 80.0 & 75.4 & 71.3 \\
\hline & & Welch & 100,0 & 100.0 & 99.8 & 99.1 & 96.8 & 92.8 & 88.4 & 83.4 & 78.9 & 74.4 & 70.3 \\
\hline & & Ayıklanmıs't & 100.0 & 100.0 & 99.9 & 99.1 & 96.8 & 93.7 & 88.9 & 84.9 & 80.5 & 75.1 & 71.2 \\
\hline \multirow{3}{*}{20} & \multirow{3}{*}{40} & Student-t & 100.0 & 99.4 & 91.6 & 78.3 & 64.8 & 53.6 & 45,3 & 38.3 & 31,9 & 27.7 & 259 \\
\hline & & Weich & 99,9 & 99.6 & 96.4 & 90.5 & 82.7 & 75.5 & 69.0 & 62.9 & 57.4 & 52.7 & 50.7 \\
\hline & & Ayiklanmiš-t & 99.3 & 99.7 & 972 & 90.8 & 84.2 & 77.3 & 71.0 & 64.4 & 59.5 & 55.4 & 51.6 \\
\hline \multirow{3}{*}{40} & \multirow{3}{*}{20} & Student-1 & 100.0 & 99.2 & 94.0 & 85.3 & 78.1 & 72.6 & 66.2 & 61.6 & 57.5 & 54.5 & 51.7 \\
\hline & & Welch & 99.9 & 97.9 & 84.8 & 69.3 & 57.2 & 48.8 & 421 & 37.5 & 33.0 & 30.4 & 27.1 \\
\hline & & Ayikianmis-t & 99.9 & 98.6 & 86.9 & 72.3 & 60,8 & 52.7 & 44.8 & 40.1 & 35.7 & 33.5 & 29.8 \\
\hline \multirow{3}{*}{20} & \multirow{3}{*}{60} & Student-1 & 100.0 & 99.7 & 95.3 & 82.8 & 69.4 & 55.8 & 44.7 & 37.2 & 30.8 & 260 & 21.8 \\
\hline & & Weich & 100.0 & 99.9 & 99.1 & 96.8 & 93.1 & 88.5 & 83.1 & 79.1 & 74.4 & 709 & 65.6 \\
\hline & & Ayiklanmis-t & 100.0 & 99.9 & 99.2 & 97.2 & 93.6 & 88.6 & 84.3 & 80.4 & 75.6 & 71.7 & 67.9 \\
\hline \multirow{3}{*}{60} & \multirow{3}{*}{20} & Student-t & 100.0 & 99.7 & 96.3 & 90.4 & 84.8 & 79.4 & 74.5 & 69.5 & 67.5 & 643 & 52.1 \\
\hline & & Welch & 100.0 & 98.8 & 85.6 & 70.4 & 58.2 & 49.5 & 41.9 & 36.9 & 33.5 & 30.4 & 27.7 \\
\hline & & Ayiklanmis-t & 100.0 & 98.8 & 88.2 & 73.9 & 61.6 & 52.7 & 45,9 & 40.2 & 36.1 & 323 & 30.5 \\
\hline \multirow{3}{*}{40} & \multirow{3}{*}{60} & Student-t & 1000 & 100.0 & 89.5 & 97.2 & 92.4 & 85.5 & 78.8 & 71.6 & 66.1 & 59.7 & 54.6 \\
\hline & & Welch & 100.0 & 100.0 & 99.6 & 98.7 & 96.0 & 91.8 & 87.6 & 82.6 & 78.6 & 73.2 & 68.9 \\
\hline & & Ayıklanmis.t & 100.0 & 100.0 & 99.9 & 98.7 & 96.3 & 92.6 & 87.8 & 83.3 & 78.2 & 74.8 & 70.2 \\
\hline \multirow{3}{*}{50} & \multirow{3}{*}{40} & Student-t & 100.0 & 100.0 & 99.6 & 973 & 93,8 & 88.4 & 83.3 & 78.5 & 742 & 702 & 67.8 \\
\hline & & Weich & 100.0 & 100.0 & 99.1 & 94.5 & 879 & 80.8 & 730 & 55.6 & 60.9 & 55.7 & 527 \\
\hline & & Ayiklanmis-t & 100.0 & 100.0 & 99.0 & 95.3 & 89.4 & 81.9 & 74.7 & 69.4 & 62.7 & 58.7 & 54.7 \\
\hline
\end{tabular}


Çizeige 5. Normal dağiiım gösteren iki populasyonda $\delta=2.0$ için elde edilen ampirik testin güca (\%)

\begin{tabular}{|c|c|c|c|c|c|c|c|c|c|c|c|c|c|}
\hline \multirow{2}{*}{$n_{1}$} & \multirow{2}{*}{$\mathrm{n}_{2}$} & \multirow{2}{*}{$\begin{array}{c}\text { Uygulanan } \\
\text { Test }\end{array}$} & \multicolumn{11}{|c|}{$a^{2} a_{1} a^{2} 2$} \\
\hline & & & $1: 1$ & 12 & $1: 4$ & $1: 6$ & $1: 8$ & $1: 10$ & $1: 12$ & $1: 14$ & $1: 16$ & $1 ; 18$ & $1: 20$ \\
\hline \multirow{3}{*}{20} & \multirow{3}{*}{20} & Student-t & 100.0 & 99.9 & 97.4 & 90.4 & 82.6 & 74.8 & 67.7 & 61.0 & 55.7 & 51.5 & 47.8 \\
\hline & & Weich & 100,0 & 99.9 & 96.7 & 89.1 & 80.2 & 71.4 & 64.2 & 57.0 & 51.5 & 47.5 & 43.9 \\
\hline & & Ayiklanmus-t & 100.0 & 99.9 & 97.2 & 90.6 & 82.2 & 74.0 & 66.5 & 61.5 & 55.9 & 50.8 & 47.0 \\
\hline \multirow{3}{*}{40} & \multirow{3}{*}{40} & Student-t & 100.0 & 100.0 & 100,0 & 99.6 & 98.7 & 96.4 & 93.4 & 90.0 & 85.7 & 81.7 & 78.5 \\
\hline & & Welch & 100.0 & 100.0 & 100.0 & 99.6 & 98,5 & 96.1 & 927 & 89.1 & 84.6 & 80.4 & 77.0 \\
\hline & & Ayiklanmis-t & 100.0 & 100,0 & 100.0 & 99.7 & 98.8 & 96.5 & 93.3 & 90.0 & 85.4 & 81.7 & 77.8 \\
\hline \multirow{3}{*}{60} & \multirow{3}{*}{60} & Student $-t$ & 100.0 & 100.0 & 100.0 & 100.0 & 100.0 & 99.6 & 98.8 & 97.6 & 96.1 & 94.1 & 91.7 \\
\hline & & Weich & 100,0 & 100.0 & 100,0 & 100.0 & 99.9 & 99.6 & 98.7 & 97.5 & 958 & 93.6 & 91.3 \\
\hline & & Ayiklanmis-t & 100.0 & 100.0 & 100.0 & 100.0 & 99.9 & 99.6 & 99.0 & 97.9 & 96.3 & 942 & 91.5 \\
\hline \multirow{3}{*}{20} & \multirow{3}{*}{40} & Student-t & 100.0 & 100.0 & 99,6 & 96.9 & 91.5 & 83.9 & 76.2 & 67.5 & 60.7 & 54.6 & 48.7 \\
\hline & & Weich & 100.0 & 100.0 & 99.9 & 99.2 & 97.3 & 94.5 & 91.2 & 86.7 & 82.8 & 78.4 & 74.6 \\
\hline & & Ayiklanmiss-t & 100,0 & 100.0 & 99.9 & 99.3 & 97.5 & 94,9 & 91.6 & 88.4 & 83.3 & 79,8 & 76.0 \\
\hline \multirow{3}{*}{40} & \multirow{3}{*}{20} & Student-t & 100.0 & 100.0 & 99.5 & 97.2 & 93.5 & 89.5 & 85.3 & 81.2 & 76.9 & 73.5 & 69.7 \\
\hline & & Welch & 100.0 & 100.0 & 97.9 & 90.6 & 82.2 & 73.8 & 65.2 & 59.5 & 53.5 & 48.5 & 44.3 \\
\hline & & Ayikdanmis-t & 100.0 & 100.0 & 98.4 & 92.7 & 84.6 & 76.9 & 68.9 & 62.2 & 57.4 & 528 & 48.3 \\
\hline \multirow{3}{*}{20} & \multirow{3}{*}{60} & Student-t & 100,0 & 100.0 & 999 & 98.5 & 95,1 & 87.8 & 80.7 & 71.3 & 63.6 & 55.8 & 49.5 \\
\hline & & Weich & 100.0 & 100.0 & 100.0 & 99.9 & 99.5 & 98.6 & 97.3 & 95.9 & 93.5 & 911 & 88.9 \\
\hline & & Ayıikanmiş-t & 100.0 & 100.0 & 100,0 & 99.9 & 99.6 & 98.9 & 97.6 & 96.4 & 94,1 & 920 & 89.3 \\
\hline \multirow{3}{*}{60} & \multirow{3}{*}{20} & Student-t & 100,0 & 100.0 & 99.8 & 98.7 & 96,3 & 93.1 & 90,3 & 87.0 & 83.4 & 81.5 & 78.4 \\
\hline & & Welch & 100.0 & 1000 & 98.3 & 91.7 & 82.5 & 73.2 & 66.1 & 59.2 & 53.8 & 49.5 & 44.9 \\
\hline & & Ayıktanmıs-t & 100.0 & 100.0 & 98.6 & 92.8 & 84.8 & $\pi 7.2$ & 69.3 & 63.4 & 57.1 & 525 & 49.1 \\
\hline \multirow{3}{*}{40} & \multirow{3}{*}{60} & Student-t & 100.0 & 100.0 & 100.0 & 99.9 & 99.6 & 98.6 & 96.8 & 93.7 & 90.4 & 86.5 & 82.7 \\
\hline & & Welch & 100.0 & 100.0 & 100,0 & 1000 & 99.8 & 99.5 & 98.6 & 96.9 & 95,2 & 93.1 & 90.5 \\
\hline & & Ayskdanmis-t & 100.0 & 100.0 & 100.0 & 100.0 & 99.9 & 99.6 & 98.6 & 97.3 & 95.5 & 93.6 & 91.6 \\
\hline \multirow{3}{*}{60} & \multirow{3}{*}{40} & Student-t & 100.0 & 100.0 & 100,0 & 99.9 & 99.6 & 98.7 & 97.2 & 94.8 & 92.2 & 89.6 & 86.9 \\
\hline & & Welch & 100,0 & 100,0 & 100.0 & 99.8 & 98.8 & 96.7 & 93.5 & 88.9 & 85.0 & 81.1 & 76.8 \\
\hline & & Ayıklaninıș-1 & 100.0 & 100.0 & 100.0 & 99.8 & 98.8 & 96.8 & 93.8 & 90.1 & 86.1 & 82.1 & 78.1 \\
\hline
\end{tabular}

$n_{1}=20, \quad n_{2}=40 \quad(n=60) \quad$ örnek genişliği kombinasyanuinda (böyük varyanslı populasyondan alınan birey sayist fazla oldugunda) Welch ve Ayiklanmig-t Testlerinin gô değerleri, populasyonlann varyanslan arasindaki fark 20 kat oluncaya kadar Student-t Testinden daha yöksek olarak gerçeklesmiştir. $n_{1}=40, n_{2}=20$ omek genişliği kambinasyonunda (küçok varyansl! populasyondan alinan birey sayisı fazla oldugunda) ise populasyoniarin varyanslari arasindaki fark 18 kat artincaya kadar Student-t Testi daha gaçlo olarak bulunmuştur. Benzer sonuçar, $n_{1}=20, n_{2}=60$ ve $n_{1}=60$, $n_{2}=20 \quad(n=B O)$ ornek genişliği kombinasyonları için de geçerlidir, $n_{1}=40, n_{2}=60$ ve $n_{1}=60, n_{2}=40 \quad(n=100)$ ornek genişlikleri kombinasyonlannda da ise butón test yŏntemleri, populasyonlarin varyanslanı arasında $20 \mathrm{~kat}$ olsa bile, \%80'in Uzerinde güç değerine ulașmaktadirlar. Bunlarin bir sonucu olarak, populasyon ortalamalari arasındako fark 2.0 standart sapma olduğunda, ornek genişilkleri eşit (en az 40'ar birey) ve populasyonlarin varyans oranlari 20 kat oluncaya kadar Student-t. Welch ve Ayıklanmiş-t Testlerinden her hangi biri lie ayni gavenilirikte kultanilabilirken, populasyoniarın varyans oranlari arttıkça ve böyok varyansli populasyondan alınan birey sayısı koç0k varyanslı populasyondan alınan birey sayisindan fazla oldukça Welch ve Ayıkdanmış-t Testieri, Student-t Testinden daha güvenilis, küçuk varyanslı populasyondan alinan birey sayısı boyok varyansit populasyondan alinan birey sayısından fazla olduğunda da Student-t Testi, Welch ve Ayıklanmıs-t Testlerinden daha govenilif olarak kullanılabileçğini ileri surmek marnkandar.

\section{Sonuç}

Bu çalışmada sonuç olarak, populasyon ortalamalar arasındaki fark sıfir ve populasyon varyanslari arasinda 20 kat fark (standart sapma cinsinden) oldugu veya populasyon varyanslari bilinmediği durumlarda ôrnek genişlikderi eşit olmak kaydiyla, ele alinan oç test yōnterninin do $1-\alpha=0.95$ goven katsayisi ile kullantlabileceği soblenebilit. Ancak ömek geniglikjerinin eşit olmadiği durumlarda, Student-t testi sadece varyans oranlan 1:1 olduğu durumlarda I. Tip hata olasiliğini beklenen seviyede gerçekleştirebildiği haide, ornek genişlikleri farkiı oldugunda, Student-t testi etkilenirken Welch ve Ayıklanmış-t testierinin I. Tip hata olasılığinı başlangiçta belirlenen \%5 sinirında korudugu goralmüștur.

Populasyon ortalamaları arasındaki fark, $\delta=0,5$ standart sapma olduğunda, populasyon varyanslan ve ornek genișlikleri eșit olmak kaydıyla ancak $n_{1}=n_{2}=60$ oiması halinde testlerin güconan govenilir gùç sibiran Içinde Kalirken, diğer boton kombinasyonlarda guç değerleri oldukça daşâk olmuştur, Ancak populasyon ortalamalari arasindaki farkin $\delta=0.5$ olmasinin, boyle bir sonuç elde etmede rolă olduğu da gỏz ardı edilmemelidir.

Populasyon ortalamalan arasındaki fark, $8=1.0$ standart sapma oldugunda, populasyon varyansları eșit olduğunda, ornek genişlikleri ve bunlann kombinasyonu ne olursa olsun testin gúcünon her yountemde güvenilit gọ̧ sınırları içinde kaimıştır. Ancak, populasyon varyanslari heterojenleştikçe, testlerin istenilen gücú 
gösterebilmesinin örnek genişlikleri ile ilișkili olduğu görölmūştür. Mesela, populasyonlarin varyans oranlan 1/6 oluncaya kadar testin gücünün $n_{1}=n_{2}=60$ örnek genişlikleri kombinasyonunda bütün yöntemlerde kabul edilebilir seviyelerde bulunmuștur. Bu durum, populasyon varyansları arasındaki fark artıkça ve örnek genişliklerinin de bäyök varyanslı populasyon lehinde dengesiz olması halinde Welch ve Ayıklanmış-t testlerinin, Student-t testine göre daha güvenilir oiduklan şeklinde yorumlanabilir.

Populasyon ortalamalan arasındaki fark, $\delta=1.5$ standart sapma ve populasyon varyanslan da eşit olduğunda, örnek genişlikleri ve bunların kombinasyonu ne olursa olsun testlerin gücônûn her yöntemde \%95'in üzerinde olarak gerçekleşmiştir. Populasyonların varyanslan heterojenleştikçe testlerin gücünūn, örnek genişlikleri ile ilișkili olduğu ve ömek genișlikleri eșit ve fazla (en az $n_{1}=n_{2}=60$ ) olduğunda, populasyon varyanslar! arasında 18 kat fark olması halinde bile her üc test yơnteminin de güç değerleri birbirine yakın ve yaklaşık \%75 olarak gerçekleşmektedir. Örnek genişliklerinin farkl olması durumlarinda da, populasyonlarin varyans oranları arttıkça ve büyük varyanslı populasyondan alınan birey sayısı küçük varyanslı populasyondan alınan birey sayısından fazla oldukça Welch ve Ayıklanmış-t Testleri, Student-t Testinden daha güvenilir, küçăk varyansli populasyondan alınan birey sayısı büyōk varyansiı populasyondan alınan birey sayısından fazla oldukça da Student-t Testi, Welch ve Ayıklanmış-t Testlerinden daha govenilir olarak bulunmuştur.

Populasyon ortalamalan arasındaki fark, $\delta=2.0$ standart sapma olduğunda ise, populasyon varyansları eşit, órnek genişlikleri ve bunların kombinasyonu ne olursa olsun testlerin güçleri her yőntemde \%100 olarak gerçekleşmiştir. Örnek genişlikleri eşit olmak şartıyla, populasyonların varyans oranları arttıkça her üç testinde güç değerlerinde de bir azalma oimaktadır. Populasyon ortalamaları arasındaki fark 2.0 standart sapma olduğunda, örnek genișlikleri eșit (en az 40'ar birey) ve populasyonların varyans oranlari 20 kat oluncaya kadar Student-t, Welch ve Ayıklanmıs-t Testlerinden her hangi biri, aynı güvenilirlikte kullanılabilirken, populasyonlarin varyans oranlari artıkça ve büyūk varyanslı populasyondan alınan birey sayısı küçūk varyanslı populasyondan alınan birey sayısından fazla oldukça Welch ve Ayıklanmış-t Testleri, Student-t Testinden daha güvenilir, küçŭk varyansilı populasyondan alınan birey sayisi bayuk varyanslı populasyondan alinan birey sayısından fazla oldukça da Student-t Testi, Welch ve Ayıklanmış-t Testlerinden daha gôvenilir olarak kullanılabileceği sonucuna varılmıştir.

\section{Kaynaklar}

Akdeniz, F, 1984. Olasilik ve Istatistik. Ankara Óniversitesi Fen Fakältesi Yayınlanı, No: 138. Ankara. $519 \mathrm{s.}$

Anonymous, 1998. Robust Determination of Mean Trimmed Mean. Erişim Adresi: http:/losprey6.npac.syr.edu:8080/ foilsets/cps713stat/node199.html. Erişim Tarihi:29.04.1999.

Devenport, J. M. and J. T. Webster, 1970. The Behrens-Fisher Problem, an Old Solution Revisited. Metrika, 22, 47-54.

Wilcox, R. R. 1986. New Monte Carlo Results of the Robustnes of the ANOVA $F, W$ and $F^{*}$ Statistics. Commun. Statist.Simula., 15 (4), 933-943.

Wilcox, R. R. 1995. The practical importance of heteroscedastic methods, using trimmed means versus means, and designing simulation studies. Brit.Jour. of Mat. and Stat. Psychology. 48 (1), 99-114.

Wilcox, R. R. 1997. A Bootstrap modification of the AlexanderGovern ANOVA method, plus comments on comparing trimmed means. Educational and Psychological Measurement, $57(4), 655-665$.

Wilcox, R, R, H. J. Keseiman and R. K. Kowalchuk, 1998. Can Test for Treatment Group Equality Be Improved - The Bootstrap and Trimmed Means Conjecture. Brith.Jour. of Math. \& Stat. Psychology. 51, Iss MAY, 123-134.

Winer, B. J. 1971, Statistical Principles in Experimental Design. Second Ed. McGraw-Hill Book Co., New York. 907 s.

Yuen, K. K. and W. J. Dixon, 1973. The approximate behavior and performance of the two-sample trimmed $t$. Biometrika $60,(2), 369-374$

Yuen, $K, K$ 1974. The two-sample trimmed $t$ for unequal population variances. Blometrika, 61 (1): 165-170.

Zar, J. H. 1999. Biostatistical Analysis. Fourth Ed. Prentice Hall Inc., Upper Saddle River, New Jersey, USA, 663 s. 